\title{
Research
}

\section{Do non-rotational ambulance-based placements affect the development of paramedic competencies from a student perspective? A qualitative study}

Leon Baranowski MSc, MEd, FHEA, MCPARA, is a Paramedic Practice Leader ${ }^{1}$ and a paramedic practitioner ${ }^{2}$; Richard Armour BParamedPrac is an Advanced Care Paramedic ${ }^{1}$ and sessional academic ${ }^{3,4}$

\section{Affiliations:}

${ }^{1}$ British Columbia Emergency Health Services, Vancouver, Canada

${ }^{2}$ Yorkshire Ambulance Service, United Kingdom

${ }^{3}$ The Justice Institute of British Columbia, Vancouver, Canada

${ }^{4}$ Charles Sturt University, Bathurst, New South Wales

https://doi.org/10.33151/ajp.17.703

\section{Abstract}

\section{Introduction}

University-led higher education for paramedics has been in place for over 20 years, with students in these programs required to complete supervised clinical placements with an experienced paramedic mentor. This investigation aims to establish whether the non-rotation of paramedic students between paramedic mentors while on ambulance-based placements aids or hinders the undergraduate paramedic student's development of competencies.

\section{Methods}

Purposive and convenience sampling methods were used, with semi-structured group interviews conducted with second year undergraduate paramedic students for data collection. Thematic analysis was used to draw meaning from the collected data.

\section{Results}

Five key themes emerged from within the data. Students reported difficulties in maintaining relationships with their assigned mentors, particularly in situations where conflicting schedules and role changes necessitated frequent rotation between mentors. Students reported feeling there was great variety in the way competency-based learning is managed by paramedic mentors, leading to inconsistencies in assessment. Students also described comparing their own personality and clinical practice against mentors, in order to self-identify more appropriate mentors during the placements.

\section{Conclusion}

This research provides an initial insight into how paramedic students perceive the effects of non-rotational ambulance-based placements on the development of competencies. Based on the findings of this research it is not possible to draw firm conclusions as to whether the non-rotation of ambulance-based placements aids or hinders undergraduate student paramedics' development of competencies. Further research is required in this area across a variety of settings in order to understand the applicability of these results.

\section{Keywords:}

paramedic; universities; mentors; competency

Corresponding Author: Leon Baranowski, leon.baranowski@bcehs.ca 


\section{Introduction}

University-led higher education for paramedics has been in place for over 20 years. In this time there have been dramatic changes in paramedic scope of practice, role and education combined with higher expectations for the delivery of exemplary patient care. At the time of writing, there are 39 universities in the United Kingdom providing 66 paramedic science programs (1). Students of these programs are required to complete a minimum number of hours of supervised ambulance-based placement with an experienced paramedic mentor during their course (2). The College of Paramedics (2) recommends a range of placements in their guidance for universities, while the use of supernumerary practice learning activities is mandated (1). Presently, the range of placements recommended generally refers to additional placements outside the setting of out-ofhospital care which are designed to reinforce clinical practice and knowledge in key areas such as maternity, minor injuries, operating theatres and coronary care units. However, whether the principle of varying placements encompasses the rotation of paramedic students through multiple ambulance stations and paramedic mentors is unclear.

The learning environment utilised by universities in the UK to reinforce its taught modules centres on a developed model of apprenticeship and work-based learning, with students required to complete a placement assessment document in conjunction with their mentor in order to assess the development of competency. The foundational concept of this model of learning is that over time the novice will become the expert (3). Lave and Wenger's (4) situated learning theory may also be considered relevant to paramedic education, as a theory that states learning should involve a process of engagement within a community of practice. However, whether the apprenticeship model of learning is restrictive or expansive to a students' learning is intrinsically linked to whether workplaces have developed structured curriculum that generate opportunities to learn broadly and deeply (3). Henderson (5) compared differences between the experience of young and mature age students of ambulance-based placements, while Boyle et al (6) found that the experience and formal and informal learning opportunities of paramedic students on ambulance-based placements are largely shaped by their viewpoints. However, little literature exists examining the relationship between the apprenticeship model of learning and how non-rotation of students impacts the attainment of competencies and experience of ambulance-based placements.

This study aims to establish whether the non-rotation of paramedic students between paramedic mentors while on ambulance-based placements aids or hinders the undergraduate paramedics students' development of competencies.

\section{Methods}

\section{Research design}

This research employed a qualitative approach, utilising semi-structured group interviews for data collection. Thematic analysis was used to identify the key themes within the data. Small group interviews were selected as the method for data collection as they allow for interactive discussion which can create greater, more in-depth understandings of perceptions, values, attitudes and experiences from numerous points of view and documents the environment in which those understandings are derived (7). A semi-structured approach to group interviews was chosen as they are well suited to the investigation of perceptions and opinions of participants regarding multi-faceted and at times sensitive issues, allowing for the probing of more information and elaboration on answers (8).

Each group interview lasted at least 1 hour but no longer than 1 hour and 30 minutes. The interviews took place in the participants' own time in a large, bright open room. Participants were seated in comfortable chairs surrounding a small table, on which an iPad with a microphone extension was placed.

\section{Sample}

Participants were selected by purposive and convenience sampling methods. An online survey was created to stratify those interested in participating in the research. Paramedic students in their second year of classes $(n=30)$ were invited to complete this survey during a fully attended practice development day.

\section{Ethical considerations}

The primary ethical consideration in this research was the protection and anonymity of the participants involved. The university was made aware of the research but was not provided details regarding the participants. Participants were not made aware of other participants' details until arrival at the interview facility and were never made aware of participants outside their interview group. During the interview process participants were allocated numbers and referred to by this number in order to anonymise the transcription process. One author had previously taught and continued to teach and assess participants during various subjects in their undergraduate studies. However, they did not function as a paramedic mentor or engage with participants during their ambulance-based placements. It is acknowledged this could have impacted on the responses provided by the participants and that this may be a potential source of bias. However, given the lack of direct involvement with participants during clinical placements this potential was considered low. 
Ethical approval was sought and subsequently granted through the University of Leeds Ethics Review Board [Ethics approval LTEDUC-036]. External research approval was sought from the participating university and following amendments was granted. Each participant provided informed consent before the interviews.

\section{Data storage}

The data created were secured according to the British Educational Research Association ethical guidelines (9) and complied with the legal requirements in relation to the storage and use of personal data as set down by the Data Protection Act. Records have been kept of disclosures which were both written and electronic. Participants are permitted to have access to the information should they request it in accordance with the Freedom of Information Act.

\section{Results}

Of the 30 students invited to participate, 22 expressed interest and were sent an email invitation to attend the group interviews. Of these 22, 12 were able to attend one of the dates selected for group interviews. Participants were subsequently grouped according to their gender, availability and location of their placement (rural or urban). Three participants were unable to attend on short notice and so nine students were interviewed in three groups of three (Table 1).

Table 1. Details of interview groups

\begin{tabular}{|c|l|l|l|}
\hline \multicolumn{1}{c|}{$\begin{array}{c}\text { Interview } \\
\text { group }\end{array}$} & \multicolumn{1}{c|}{$\mathbf{1}$} & \multicolumn{1}{c|}{$\mathbf{2}$} & \multicolumn{1}{c|}{$\mathbf{3}$} \\
\hline \multirow{4}{*}{ Demographics } & Male $(\mathrm{N}=2)$ & Male $(\mathrm{N}=2)$ & Male $(\mathrm{N}=1)$ \\
& Female $(\mathrm{N}=1)$ & Female $(\mathrm{N}=1)$ & Female $(\mathrm{N}=2)$ \\
& Rural $(\mathrm{N}=2)$ & Rural $(\mathrm{N}=2)$ & Rural $(\mathrm{N}=1)$ \\
& Urban $(\mathrm{N}=1)$ & Urban $(\mathrm{N}=1)$ & Urban (N=2) \\
\hline
\end{tabular}

During thematic analysis five key themes emerged from the data in relation to the undergraduates' development of competencies. In order of dominance, these were: Studentmentor relationship, Learning environment, Competency-based development, Learning strategies and Student perspective.

\section{Student-mentor relationship}

While the student-mentor relationship was generally described as professional and seeking to provide students with a positive experience, students also reported that owing to frequently changing timetables, shift patterns and role changes by the mentor it was often difficult to maintain a relationship with the same mentor for the entire program, if indeed the student and mentor were compatible at all. Several students conveyed that they felt an informal introduction should be arranged where students and mentors have the opportunity to meet outside the formal learning environment, as there was a perceived additional pressure on their first day of clinical placements.
Female student - rural station

'The person I was with initially was just... made me feel uncomfortable, not on purpose, I just think we weren't personality matched. We get on now, it's really only the last 4 months that I've got pretty much settled in and happier with the job'.

Female student - urban station

'Am a bit of a spare part in the bus, we don't really talk on shifts anymore and it's got to the part where it's really strange. If they mention something to me about physiology and I ask 'what's that?' - they say 'are you thick?' They just make me feel rubbish because they've taught me the basics and the fundamentals of what I need to know but I think they could've done it in a nicer way'.

Although there were a number of credible examples of positive learning environments, where the student-mentor relationship was negative, students described seeking out alternate mentors independently due to their negative learning experience. However, this approach to ambulance-based placements did appear to heighten stress with a perceived pressure to perform in the initial shifts with new mentors.

\section{Female student - urban station}

'I've gone out with a few more people in the last few months and started to enjoy shifts, started to realise banter on shifts is normal and I don't always have to sit in the back'.

Male student - urban station

'I've realised that if you get around you see different setups and approaches and different ways of doing things. So I try to get on with as many people as possible. You do have that problem, though, when you go out with a new person you have to prove that you're competent straight away otherwise you don't get a chance to do much'.

\section{Learning environment}

Overall, students reported enjoying the learning environments they were exposed to. However, a large proportion of students identified the restrictiveness of their learning environments and often spoke about repetition while on placements and the lack of broader learning opportunities. Students particularly expressed concerns over a lack of specific incidents, including maternity and trauma, in their placements.

Male student - rural station

'I suppose the only thing negative from my point of view is that it's not rural but not an urban station, and travelling and transport to hospital l've pulled in fewer jobs than l'd like... my previous experience was more urban based and we pulled a lot more jobs in that station'. 
Male student - rural station

'Where I am there's quite a lot of breathing difficulty jobs... so you seem to become good at one assessment type really... there's not too much varied in that sense so it can be a bit frustrating at times'.

\section{Competency-based development}

What appeared instantly apparent during the group interviews is that competencies are generally viewed as 'tick-box exercises', rather than a tool to record and track the development of skills and competencies. Students raised the question about the definition of competence and how mentors perceive competence.

Female student - rural station

'I don't think a single paramedic on the road cares about the competencies in the back of your folder'.

Female student - rural station

'It seemed a bit random some of the things you had to get signed off. I think my mentor felt that as well as she didn't understand the thinking behind a lot of them'.

Some students reported finding that mentors will sign off a competency 'in good faith', whilst some will refuse to sign off a competency unless they themselves directly supervise it.

Female student - urban station

'The biggest problem with competencies is that mentors don't really know who's allowed to sign them, we don't know who can sign'.

Female student - rural station

'I could come along and do a cannulation and the technique was right... but the flush doesn't go through... does that count as a successful cannulation? The technique was correct but... you didn't get the result you wanted. So who gets to say that, that was the right thing?'

\section{Learning strategies}

Students frequently reported feeling they had to portray a more reserved character whilst on placement such that they would not be judged by other members of staff. Several female members made note of encountering sexist attitudes and remarks while on placement.

\section{Male student - rural station}

'You want to make a good impression straight away... so I kind of chose a quieter tact'.

Female student - rural station

'One guy in particular is constantly... sexist. Sexist as well as saying we used to do a fitness test in the old days... could I do that?'

It emerged during the interviews that no student followed the proposed timetables and patterns of working, often reporting issues with the transition to night shifts and working longer days.

Male student - urban station

'I started off mostly working days because it was easier education and now I prefer to work from four until two'.

\section{Student perspective}

It appears that students compare themselves not just personally, but also clinically from the start of their placements. The data suggests that the majority of participants at points during their ambulance-based placements compared their practice with that of their mentors, other clinicians and other students. Almost all students drew comparisons between university education and their ambulance-based placement, however, one-third were specific in identifying these as practice gaps.

Male student - rural station

'I didn't want to be the guy before. I heard straight away about him from my mentor who said he came in and was very loud, patronising and quite arrogant and I didn't want to come across like him'.

\section{Discussion}

This research examined how non-rotational ambulance-based placements affected the attainment of required competency. For two individuals usually unknown to each other, adopting the student-mentor roles presupposes that they are able to communicate with each other, develop a rapport and cultivate a working relationship (10). Multiple students identified difficulties in maintaining or cultivating an effective student-mentor relationship, particularly when they were perceived to be not compatible at all. Where students felt the relationship was not conducive to a positive ambulance-based placement, it was common practice to independently seek out an alternative mentor. It was subsequently identified that pre-placement visits may improve the quality of the relationship, or provide an early indication when a relationship may not be favourable in facilitating an effective learning environment. Such preplacement visits were introduced in the field of nursing to reduce anxiety levels of students attending clinical placements. Price (11) identified that this reduction in stress surrounding new placements benefits the learner and ultimately patients as a tendency to work more effectively without the stress of facilitating a student-mentor relationship was observed.

Although students overall reported satisfaction with the learning environments during ambulance-based placements, there was a recognition that there was an element of restrictiveness and lack of broader opportunities while on placement. Where students self-identified these issues during their ambulancebased placement, they would often attempt to arrange additional placements on specialist response vehicles, such 
as the rapid response vehicle. However, these vehicles did not totally ameliorate the situation as students reported a lack of foundational education in the most commonly attended incidents; alcohol and social-related incidents. It was also recognised that the growing trend for specialist units within ambulance services limited the opportunity to provide advanced medical and trauma care.

The development of student competency is the core of ambulance-based placements and the learning environment. However, this was not felt to be the case by students who considered competencies to be 'tick-box exercises'. This was apparently compounded by variability in the assessment of competence between mentors, particularly when the student was unable to work with their assigned mentor for prolonged periods of time. Although the placement assessment document provided by universities does include definitions of competence, there is a clear disconnect between student, mentor and institutional expectations of how competency is achieved and demonstrated.

Although it can be intimidating to enter a new environment, the question must be raised as to whether students should be expected to adapt their personalities to gain respect from staff and ensure learning opportunities are made available to them. It was commonly reported by students that they felt the need to modify their personality or behaviour to suit their mentor's expectations in order to ensure they received a fulfilling ambulance-based placement. Particularly alarming was the number of female students who reported ongoing issues with sexism during their ambulance-based placements, a clearly unacceptable behaviour which no student should be expected to manage. It was also important to note that for those without prior experiencing working long shifts, 10 and 12 hour days were considered exhausting and that alongside the active learning this was overwhelming for students, particularly when transitioning to night shifts.

Although one-third of students identified the differences between university education and ambulance-based placements as practice gaps, most suggested the responsibility for addressing this gap lay with the university. Students expressed the belief that all required knowledge should be taught in the university setting, with ambulance-based placements serving as an opportunity to practise these skills. In reality, university education plans to teach students the core knowledge and skills required to attend the clinical placement. This discourse appeared to bring into question whether students are creating a theory-practise gap within their own education through a lack of clarity about the structure of their education, or whether their mentors are contributing to this gap by failing to understand their role in transitioning knowledge into practice.

\section{Limitations}

The primary limitation of this research was the single-centre sample with associated small sample size. With over 39 universities providing higher level education for paramedics, further research must evaluate the external validity of these preliminary findings across the United Kingdom.

\section{Conclusion}

This research provides an initial insight into how paramedic students perceive the effects of non-rotational ambulancebased placements on the development of competencies. Based on the findings of this research it is not possible to draw firm conclusions as to whether the non-rotation of ambulance-based placements aids or hinders undergraduate student paramedics' development of competencies. In general, it appears that when non-rotation does begin to hinder the attainment of competencies students independently seek out further learning opportunities to enhance their ambulance-based placement. Conversely, this appears to contribute to stress in students who may feel pressure to perform at an unreasonably high level when working with new mentors. Further, a lack of clarity around the definition and assessment of competence between student and mentor and personality conflict may further contribute to a desire to rotate through mentors during ambulance-based placements. Further research should investigate the applicability of these preliminary findings across a broader range of universities and ambulance trusts.

\section{Conflict of interest}

The authors have no competing interests. Each author of this paper has completed the ICMJE conflict of interest statement.

\section{Funding}

No funding was received.

\section{References}

1. Health and Care Professions Council. Homepage [Internet]. London, United Kingdom; HCPC; Cited December 2019. Available at: www.hcpc-uk.org

2. The College of Paramedics. Paramedic Curriculum Guidance \& Competence Framework, 5th edn. Bridgewater: College of Paramedics; September 2019. Available at: www.collegeofparamedics.co.uk/publications/professionalstandards 


\section{References (continued)}

3. Fuller L, Unwin L. Towards expansive apprenticeships: a commentary by the Teaching and Learning Research Program. London: University of London; 2008. Available at: http://learning.gov.wales/docs/learningwales/ publications/140721-towards-expansive-apprenticeships-en. pdf

4. Lave J, Wenger E. Situated learning: legitimate peripheral participation. Cambridge, United Kingdom: Cambridge University Press; 1991.

5. Henderson T. Influence of life experience on undergraduate paramedic students placements. Journal of Paramedic Practice 2012;4:585-92. doi: 10.12968/jpar.2012.4.10.585

6. Boyle M, Williams B, Cooper J, Adams B, Alford K. Ambulance clinical placements - a pilot study of students' experience. BMC Med Educ 2008;8(19). doi: 10.1186/14726920-8-19

7. Vaughn S, Schumm J, Sinagub J. Focus group interviews in education and psychology. Thousand Oaks, USA: Sage Publications; 1996.

8. Barriball K, While A. Collecting data using a semi-structured interview: a discussion paper. J Adv Nurs 1994;19:328-35. doi: 10.1111/j.1365-2648.1994.tb01088.x

9. British Education Research Association. Ethical guidelines for educational research. London: BERA; 2011. Available at: www.bera.ac.uk/wp-content/uploads/2014/02/BERA-EthicalGuidelines-2011.pdf?noredirect=1

10. Gopee N. Mentoring and supervising in healthcare. London, United Kingdom: Sage; 2011.

11.Price R. Moving wards - how do student nurses cope? Nurs Times 1985;85:32-5. 